\title{
A Hybrid MCDM Model for New Product Development: Applied on the Taiwanese $\mathrm{LiFePO}_{4}$ Industry
}

\author{
Wen-Chin Chen, ${ }^{1}$ Li-Yi Wang, ${ }^{2}$ and Meng-Chen Lin ${ }^{1}$ \\ ${ }^{1}$ Department of Industrial Management, Chung-Hua University, No. 707, Section 2, WuFu Road, Hsinchu, Taipei 30012, Taiwan \\ ${ }^{2}$ Program of Technology Management, Chung-Hua University, No. 707, Section 2, WuFu Road, Hsinchu, Taipei 30012, Taiwan \\ Correspondence should be addressed to Wen-Chin Chen; wenchin@chu.edu.tw
}

Received 20 May 2014; Accepted 13 November 2014

Academic Editor: Zhike Peng

Copyright ( 2015 Wen-Chin Chen et al. This is an open access article distributed under the Creative Commons Attribution License, which permits unrestricted use, distribution, and reproduction in any medium, provided the original work is properly cited.

\begin{abstract}
Recent years, since problems with respect to atmosphere pollution hasten countries to accentuate green-related policy regarding the sustainable energy, the lithium-iron phosphate $\left(\mathrm{LiFePO}_{4}\right)$ battery has been appealed to the world. However, more and more firms invest the $\mathrm{LiFePO}_{4}$ batteries production that has launched a fierce competition. Successful new product development (NPD) processes have been considered the key for $\mathrm{LiFePO}_{4}$ battery firms to increase their competitive advantage. Firms must make correct decision faster due to the rapid development of technology and the decreasing product life cycle. This study proposes a hybrid multiple criteria decision making (MCDM) model based on the literature review and consultation with the experts, interpretive structural modeling (ISM), and fuzzy analytic network process (FANP) for evaluating various strategies for NPD. First of all, reviewing of literature and meeting with the experts are used to screen factors and select the criteria. Then, an ISM is managed to determine the feedback and interdependency of those factors in a network. Finally, a fuzzy theory is applied to resolve the linguistic hedges and an ANP is adopted to obtain the weights of all the factors. A case study is undertaken to validate the model in a Taiwanese company that provides professional packing and design for lithium-iron phosphate battery.
\end{abstract}

\section{Introduction}

It has been a global issue to make the world a low carbon place supported by sustainable energy due to the limited oil storage and the global warming. For this reason, people have been looking for effective and environment friendly energy storage devices for the sustainable energy to solve the problems. For this reason, the lithium-ion (Li-ion) batteries (LIB) have been attracting wide attention, lithium-iron phosphate $\left(\mathrm{LiFePO}_{4}\right)$ especially. Even though many types of Li-ion batteries such as lithium cobalt oxide $\left(\mathrm{LiCoO}_{2}\right)$, lithium manganese oxide (LMO), and lithium nickel manganese cobalt oxide (NMC) are common in consumer electronics, lithium-iron phosphate $\left(\mathrm{LiFePO}_{4}\right)$ has been deemed the most promising one for the next generation Li-ion battery due to its inherent merits such as low cost, low toxicity, long cycle ability, and high safety. $\mathrm{LiFePO}_{4}$ battery firms have developed a number of lightweight, high energy density products including portable devices, power tools, and electric vehicles. $\mathrm{LiFePO}_{4}$ batteries are replacing the lead acid and other batteries which have been historically used. It seems that the $\mathrm{LiFePO}_{4}$ battery industry is currently one of the most valuable industries in Taiwan. However, since more and more firms invest huge amount of money in the $\mathrm{LiFePO}_{4}$ batteries, they are facing an extremely competitive and cost-cutting war. The increasing demand for $\mathrm{LiFePO}_{4}$ batteries has led the firms and academics to stress on new product development (NPD) projects concerning the environmental topics to gain and maintain a competitive edge. However, not all of the NPD projects could reach the business goal and keep the competitive advantage. The strategies of proposed projects must be precisely assessed to see if they meet the business's objectives before they move forward. From John Goodenough's research group published literature in 1997 to present, continuous efforts have been improving the performance of $\mathrm{LiFePO}_{4}$. However, although plenty of researches provide solutions for $\mathrm{LiFePO}_{4}$ batteries, a discussion on evaluation of new product development projects for $\mathrm{LiFePO}_{4}$ batteries is rare. 
The first significant step to evaluate strategies of new product development projects for $\mathrm{LiFePO}_{4}$ battery firms is to recognize the critical success factors (CSFs). In today's fast-paced, fiercely competitive world, identifying the critical success factors of new product development projects separates the successful $\mathrm{LiFePO}_{4}$ batteries firms from their competitors. The critical success factors are high-level criteria for the firms to make qualified strategies. However, it is not easy for firms to assess those critical factors because numerous problems could affect the evaluation of NPD projects. For example, time in developing new products is one of the essential factors to reach the ultimate business purpose because of the decreasing life circle of products and the rapid growth of technology. Besides, recent years, due to the depleting fossil fuel and global warming threats, environmental issues prompt firms to design green-related products and encourage them to adopt green energy for NPD projects, particularly for the energy companies. In addition to time and environmental reasons, many more aspects need to be incorporated into the NPD projects assessment including finance, technology, design, manufacture, team work, and marketing. Unfortunately, not all of factors are aligned with the ultimate profit goal. Managers need to choose right strategies in the NPD projects, policies, and practices to provide reasonable assurance and to avoid unpredictable impact on the business. Thus, the $\mathrm{LiFePO}_{4}$ batteries firms have to look for a systematic way to fast response to those demands so as to appropriately judge the critical success factors of NPD project and precisely make strategies.

Since the demand for effective energy storage devices is increasing, the $\mathrm{LiFePO}_{4}$ battery with outstanding performance is believed to be the most promising candidate for the sustainable energy. $\mathrm{LiFePO}_{4}$ battery firms have to seek beneficial investments such as international cooperation, new product development, and equipment update in order to survive in this highly competitive global economy. New product development is deemed the most difficult among the investments. In general, the cost of new product development, the number of developing team member, and the duration of a project are in direct proportion. Besides, firms need to pay for equipment and tools for manufacturing. It is not easy for firms to develop an unflawed product. It actually takes a great deal of time and money to successfully develop a new product. New product development projects give the managers challenges on decision making, regulation change, manufacturing details, time stress, market economy, producing schedule, customer needs, member diversity, and team work. As a result, an efficient assessment model for new product development projects is the first priority solution in the $\mathrm{LiFePO}_{4}$ battery industry.

Although it is hard to find studies in the field of evaluating NPD projects for $\mathrm{LiFePO}_{4}$ batteries, researchers have employed various methodologies for firms in many other industries. One of the most applied approaches to solve the problems of performance assessment with numerous factors is using multiple criteria decision making (MCDM) methods. The analytic hierarchy process (AHP) has been widely recognized as a distinguished decision making method in a variety of fields pertaining to a multiple criteria decision making problems. Although the AHP has become a popular application for performance assessment, each individual criterion is assumed to be independent. In order to deal with the limitation of AHP, the analytic network process (ANP) method has been largely used to solve the interdependency issue. The ANP approach replaces the AHP with a network that allows for complicated relationships among criteria as well as subcriteria. Current multiple criteria decision making models may be considered to help the $\mathrm{LiFePO}_{4}$ battery managers solve their problems. However, existing models lack a holistic solution. As a result, a wrong and misjudged decision may cause unpredictable impact on the firms. According to the analysis and comparison with above methods, it is vital for researchers to use advantaged method for creating an evaluation model.

The members of decision makers working on the new product development projects are usually formed by a group of managers. If they make wrong decisions, it will cause a great loss to enterprise in finance. For this reason, the chance of wrong decisions can be decreased to the lowest if a suitable assessment model is provided in advance for new product development projects. The increasing demand for $\mathrm{LiFePO}_{4}$ batteries has launch an extremely competition. It is not allowed the firms to hesitate to choose NPD projects. The main purpose of this study is to help the $\mathrm{LiFePO}_{4}$ battery managers precisely evaluate the critical success factors in NPD projects and efficiently make correct decisions. In order to achieve the research objective, this study would propose a synthetic MCDM appraisal model using a step by step method. At first, literature reviews and expert opinions are employed to identify the criteria of NPD projects. After getting done the critical success factors selection, an interpretive structural model (ISM) is managed to determine the feedback and interdependency of those criteria in a network. Finally, a fuzzy theory is applied to resolve the linguistic hedges. An analytic network process (ANP) is adopted to obtain the weights of all the factors and to summarize the result. A real case study is presented for the NPD projects evaluation in a Taiwanese lithium-iron phosphate battery company to validate the model.

The rest of this study is organized as fallows. Section 2 goes through the literature on the subjects and methodologies adopted in this study. Section 3 establishes a hybrid MCDM model for NPD evaluation. A case study of Taiwanese $\mathrm{LiFePO}_{4}$ battery product design is carried out to verify the practicality of the proposed system in the next section. The last section sums up this research.

\section{Literature Review}

Since the large amount of demand for the sustainable energy, lithium-iron phosphate battery firms have to carefully evaluate the critical success factors in NPD projects and efficiently make correct decisions. The firms have to utilize a systematic model to solve the problem so as to maintain the competitive edge. In order to arrive at the ultimate business purpose, this study investigates the previous researches before establishing the integrated MCDM model in new product development 
processes and applying to the Taiwanese $\mathrm{LiFePO}_{4}$ battery company. Hence, this section is going to discuss previous studies pertaining to the new product development (NPD), $\mathrm{LiFePO}_{4}$ battery industry, interpretive structural model (ISM), and fuzzy analytic network process (FANP).

2.1. NPD. The improvements in technology, equipment, and raw material do not increase the product life circle in this high competitive product design environment. In fact, the product life circle is getting short. Enterprises have to continuously focus on new product innovation in order to enhance customer satisfactions, product value, and opportunities. Existing products can probably keep a firm stable but new products are the motivation that makes a firm thrive. Therefore, enterprises in any industry need to make a right decision in NPD project selection to assure the advantages over others. In other words, NPD is considered as the key for firms to maintain the competitive advantage [1-4]. Because of the potential for firm failure and the missteps in new product development, understanding NPD within the new venture context is critical [5]. Since NPD is the core management in enterprises, they need to have the capability of creation, innovation, enforcement, technology, teamwork, and integration. Each step during the development procedure has a great impact on NPD including customer needs, competitor intimidation, technical risk, department cooperation, and the resource derivation. Besides, although the ability to design a new product can enhance the competition in the market, enterprises have to face more impacts on vagueness, uncertainty, resource allocation, and potential benefits in market places.

A successful NPD is an important source of survival and competitive advantage for enterprises [6]. It not only makes a business sustainable development but also helps a business against difficulties during depression. When businesses evaluate performances in NPD projects, they use five criteria based on profits: product quality, product cost, development time, development cost, and development capability. Those criteria are built by stakeholders in enterprises consisting of staff in development and other departments and other NPDrelated members. The NPD group may feel like designing extraordinary products and the manufacturing operators may regard job opportunities created by NPD. Since both of the employees and customers expect to follow the high safe standards, it probably conflicts with the profit purpose. Other members may not have any connection with enterprises and products but they would still like the products to meet environmental protection and to reduce the harmful waste emission [7]. NPD contains two high relation criteria technology feasibility and market profitability. As to the NPD performance, effective and efficient are the main criteria. Effective is about doing the right things while efficient is about doing the things with the right manner. Enterprises may employ different methods to assess performance in light of their features, strategies, and designs. The methods can be performance measurement balance matrix, performance measurement, performance measurement questionnaire, Cambridge performance measurement design process, performance criteria system, or performance measurement integration model.
2.2. $\mathrm{LiFePO}_{4}$ Battery Industry. An ever-increasing demand for portable electronic devices drives technological improvements in batteries. In addition, due to oil depletion and climate change, establishing a low carbon environment supported by sustainable energy has been a global topic. As an effective energy storage device for the sustainable energy, $\mathrm{LiFePO}_{4}$ in the lithium-ion batteries has been playing a significant role. An earlier study by Padhi et al. [8] shows $\mathrm{LiFePO}_{4}$ is inexpensive, nontoxic, and environmentally benign and it is going to be an excellent candidate for the cathode among low-power, rechargeable lithium batteries. From Goodenough's research group published literature in 1997 to present, continuous efforts have been improving the performance of $\mathrm{LiFePO}_{4}$. Goodenough [9] pointed out challenges for rechargeable batteries such as cost, safety, energy, density, life, and rate. This paper indicated that the traditional rechargeable batteries have good rate capabilities but limited energy density and gave strategies to increase the specific capacity for lithium-ion batteries. However, although plenty of researches provide solutions for $\mathrm{LiFePO}_{4}$ batteries, a discussion on evaluation of new product development projects for $\mathrm{LiFePO}_{4}$ batteries is rare.

Previous researches reviewed the development of $\mathrm{LiFePO}_{4}$ in the past years as well as discussing some issues for $\mathrm{LiFePO}_{4}$ in the future. Ellis et al. [10] reported a new low-cost and environmentally friendly solvothermal process to prepare $\mathrm{LiFePO}_{4} \mathrm{~F}$ as a promising electrode material for lithium-ion batteries because of its good energy storage capacity and electrochemical, thermal stability. Wang and Sun [11] indicated that olivine $\mathrm{LiFePO}_{4}$ has been the low-cost, high performance cathode material for lithiumion batteries. They discussed the further development of $\mathrm{C} / \mathrm{LiFePO}_{4}$ composite. Yuan et al. [12] also found out the olivine-structured $\mathrm{LiFePO}_{4}$ has long life span, abundant resources, low toxicity, and high thermal stability. Based on those green and sustainable features, they thought that $\mathrm{LiFePO}_{4}$ in the lithium-ion batteries is prominent and has become a competitive candidate of cathode material for the battery system. Above research studies considered the olivine $\mathrm{LiFePO}_{4}$ as the most competitive cathode candidate for the next generation of green lithium-ion battery. They all highlight recent development of $\mathrm{LiFePO}_{4}$ with its inherent merits including good energy storage capacity, abundant resources, high energy density, high thermal stability, low toxicity, low cost, long cycle ability, and high safety. Since many investigations demonstrate that the $\mathrm{LiFePO}_{4}$ battery has been attracting wide attention, this study endeavors to streamline the NPD process in the $\mathrm{LiFePO}_{4}$ battery industry.

2.3. ISM. The interpretive structural modeling (ISM) is an interactive learning process in which a set of different but directly related elements is formed into a comprehensive systematic model [13-15]. The interpretive structural modeling (ISM) is a tool, which applies to the management decision making system of social science to solve some problems, such as finding the connection by analyzing diversified messages and integrate the construction of the association model elements. ISM interprets the correlation between elements 
according to the discrete mathematics of binary logic and presents the relationship between elements by hierarchical structure through the application of the basic concepts of the graphic theory. In case of unclear problem structure, Warfield [16] proposed the method of ISM to determine the correlation structure of the problem by model construction through information integration. When the complexity of a system increases along with structural increase, ISM is needed to aid the model construction. Tatsuoka [17] suggested that there is a correlation between conceptual elements. Hence, through thinking, all the elements of the system with specific causal relationship between in elements can be incorporated into a two-dimension square relationship matrix (subordinate). The matrix is multiplied until the values inside the matrix are stable and compared with the previous relationship matrix in model construction. The intersection of the two matrices is obtained to determine the correlation between elements and construct the structural model accordingly.

ISM has been increasing applied to various fields of study to identify the interrelationship among elements regarding the issue. A current research gave an overview about the key concept of ISM approach which was discussed in detail [18]. Various steps involved in ISM are widely used by researchers but the final digraph is usually ignored. The digraph from the conical form of reachability matrix is generated by nodes and lines of edges [19-22]. Anantatmula and Kanungo [23] used the ISM method to construct the relationships between IT (Information Technology), KM (Knowledge Management), and environmental improvement items and further identified the success factors that can affect project management performance and structure. Bhattacharya and Momaya [24] studied construction companies in India using the ISM method and proved that ISM can effectively enhance the construction company's capabilities and deal with customer needs in case of complex projects in terms of quality and delivery time. A case study in Taiwan proposes an effective hybrid process for evaluating district development directions concerning district revitalization and regeneration by ISM and other methods [25].

2.4. FANP. Analytic Hierarchy Process (AHP) proposed by Saaty [26] assumes that the criteria (effecting factors) in the same level are mutually independent. Because such assumption does not reflect the reality, Saaty [27] proposed the analytic network process (ANP) to extend AHP by gathering dependency and feedback with AHP. The purpose of the ANP method is to improve the traditional AHP structure in which the criteria in the same level are not interactive and dependent. In the real world, the factors influencing decision making is no long limited by the linear structure that flows from up to down. In other words, it is more like a network rather than a linear type as one hierarchy may dominate or be dominated by other hierarchies, namely, the feedback effects. ANP tolerates criteria with feedback in the same cluster (inner dependence) and allows the criteria feedback in different clusters (outer dependence). Researchers can identify the relationship among criteria in a cluster and the relationship among the clusters and then infer the priority of the alternatives.
Many previous studies have used FANP to solve the complex problems in a decision making model and chose the best alternative or strategy by fuzzy weights. Mikhailov and Singh [28] published an extended ANP approach that includes personal preference, transfers fuzzy evaluation values to range values by $\alpha$-cut method, and obtains the weights in light of the range value to design a decision making system. Promentilla et al. [29] applied the ANP technique to analyze the polluted yards and assess the improvement strategies. The procedure of their methodology is to apply the $\alpha$-cut method, interval arithmetic, and fuzzy optimism index to the definite matrix and then find out the priority weights by calculating the eigenvalues. Each value in the pairwise comparison matrix represents the subjective opinions of a decision maker. Associating ANP with fuzzy theory can demonstrate the fuzzy consensus from the group evaluators' point of views on the importance between any two criteria. Büyüközkan et al. [30] introduced the fuzzy number to the super-matrix using the linguistic assessment and the fuzzy algorithm to solve the fuzzy problems arising from the process of the criteria selection and judgments. Mohanty et al. [31] employed FANP method to analyze the risks and uncertainty for investments that is to calculate the weights based on scope analysis and to select the best $\mathrm{R} \& \mathrm{D}$ project by fuzzy cost analysis. A FANP method is capable of providing enriched insights for strategic management in the Turkish airline industry [32]. Chen and Chang [33] employed ISM to obtain the dimension-dimension and criterion-criterion dependence relationship and used the Fuzzy Analytic Network Process (Fuzzy ANP) to determine the top priority weight for assessment improvement in the new product development solutions of the enterprises.

FANP is one of the most popular MCDM models used to select suitable projects, suppliers, locations, and so on. Previous paper presented an integrated model to evaluate different available technologies for NPD by using ISM and FANP methods in a flat panel manufacturer. A hybrid MCDM method based on FANP was adopted for investors to select the green house locating in Iran [34]. The ANPbased method presented a multistep process for an Indian automobile components manufacturing company to choose a third-party reverse logistic provider [35]. Another paper developed a model based on ISM, benefits, opportunities, costs, and risks concept (BOCR) and FANP in order to select the most suitable solar cell technology for firms in new product manufacturing.

\section{Proposed Structure for $\mathrm{LiFePO}_{4}$ in NPD}

This study employs ISM and FANP to make new product investments more advantageous to the $\mathrm{LiFePO}_{4}$ battery industry. The procedure passes through three phases with those methods to complete the study. In the first phase, factors affecting NPD are collected and analyzed from the related studies and eight experts from different departments of $\mathrm{LiFePO}_{4}$ lithium-ion battery industry. Five criteria and sixteen subcriteria are identified to be conducted in this study. As to the second phase, an ISM is managed to distinguish 
the relationships among the criteria (outer dependence) and among the subcriteria (inner dependence) for the hierarchical structure after figuring out all the factors by the literature reviews and expert interviews. In the meanwhile, a questionnaire for the expert interviews is undertaken across the $\mathrm{LiFePO}_{4}$ battery divisions. In the third phase, a supermatrix is created by using a FANP, and the weights of all the criteria are computed. A determination of the ranking weights shows the priority of the critical success factors in a new product project.

First Phase: Identifying the Evaluation Criteria of NPD. In order to assess the criteria, an expert committee is established. In this phase, factors affecting NPD are identified according to literature review and the decision making committee's opinion. Then, the most significant factors are determined to be the evaluative criteria and subcriteria.

Second Phase: Forming the Network Structure. A hierarchical structure is formed based on the relationship among the criteria and within the subcriteria by utilizing an interpretive structural modeling (ISM) method. The ISM also builds a network relationship map. The ISM method is performed in the following steps in this study.

(1) In this step, an adjacency matrix that shows the contextual relationship among the subcriteria under each criterion is formed. Questionnaires are prepared firstly to identify the contextual relationship between any two criteria and the associated direction of the relation. The number of times of experts' judgments on the relationship between each pair of criteria is counted. A threshold value of $88 \%$ is used to determine if the criteria are dependent. That is, if the number of times is less than $88 \%$, a 0 is set as there is no influence between the criteria; if the frequency of experts' agreement is greater than or equal to $88 \%$, then a 1 is set. For instance, there are $n$ criteria in an adjacency matrix, $e_{i}$ and $e_{j}$ are, respectively, the $i$ th and the $j$ th subcriteria of a criterion, and $\pi_{i j}$ is the relation between the $i$ th and the $j$ th subcriteria of the criterion. If $e_{i}$ influences $e_{j}$, then $\pi_{i j}=1$; otherwise, $\pi_{i j}=0$. The adjacency matrix $D$ will be presented as in the following formulation:

$$
D=\begin{gathered}
e_{1} \\
e_{2} \\
\vdots \\
e_{n}
\end{gathered}\left[\begin{array}{cccc}
e_{1} & e_{2} & \ldots & e_{n} \\
0 & \pi_{12} & \ldots & \pi_{1 n} \\
\pi_{21} & 0 & \ldots & \pi_{2 n} \\
\vdots & \vdots & \ddots & \vdots \\
\pi_{m 1} & \pi_{m 2} & \ldots & 0
\end{array}\right]
$$

(2) This step develops the reachability matrix and check for transitivity. An initial reachability matrix $M$ is calculated by adding the matrix $D$ from step 1 with a unit matrix $I$ shown in formula (2). The operators of the Boolean multiplication and addition are then used to compute the final reachability matrix $M^{*}$.
The reachability matrix $M^{*}$ is processed by a convergence of the matrix $M$ represented in formula (3):

$$
\begin{aligned}
M & =D+I, \\
M^{*} & =M^{k}=M^{k+1} \quad k>1 .
\end{aligned}
$$

(3) Based on the reachability matrix $M^{*}$, all the interdependencies among criteria and subcriteria are depicted.

(4) Complete the ISM hierarchical structure.

Third Phase: Obtaining the Priority Order of the Strategies. This phase is to derive the weights of the criteria and subcriteria in new product design by using a fuzzy analytic network process (FANP). This study employs the nine-point scale of relative importance proposed by Saaty [36] to design the FANP questionnaire. The experts playing decision makers in the $\mathrm{LiFePO}_{4}$ battery industry are conducted in the survey. The FANP is processed as follows.

(1) Form the network structure in which the goal, the criteria, and subcriteria are well defined and the relationship of the exterior among the criteria and the relationship of interior among the subcriteria are determined in the last phase.

(2) Form pairwise comparison matrices with the 1 to 9 scores received from each of the $K$ experts' responses in the questionnaires.

(3) Obtain the weights and analyze consistency. The priority of the criteria can be compared by the calculation of eigenvectors and eigenvalues:

$$
\begin{gathered}
w_{i}=\frac{1}{n} \sum_{j=1}^{n} \frac{a_{i j}}{\sum_{i}^{n} a_{i j}} \quad \forall i=1,2, \ldots, n, \\
A \times w=\lambda_{\max } \times w,
\end{gathered}
$$

where $w$ is the eigenvector of matrix $A$ gained from formula (4) and $\lambda_{\max }$ is the largest eigenvalue in the matrix $A$. The pairwise matrixes are then examined with consistency index (C.I.) and consistency ratio (C.R.) to see if each pairwise comparison matrix reaches the consistency. According to Saaty [37], the acceptable C.R. range is based on the size of matrix, that is, 0.05 for a $3 \times 3$ matrix, 0.08 for a $4 \times 4$ matrix, and 0.10 for all larger matrixes. If the value of C.R. is more than the threshold, the consistency test is not passed and the original entries in the matrix need to be reviewed and revised by the decision maker.

(4) Create fuzzy positive matrixes. The entries in the pairwise comparison matrixes are transformed into positive triangular fuzzy numbers known as linguistic variables. As suggested by Buckley [38], the fuzzy positive reciprocal matrix can be defined as the following formula:

$$
\widetilde{R}^{k}=\left[\widetilde{r}_{i j}\right]^{k}
$$


where $\widetilde{R}^{k}$ is a positive reciprocal matrix of decision maker $k$; $\widetilde{r}_{i j}$ is relative importance between decision factors $i$ and $j$;

$$
\begin{aligned}
& \tilde{r}_{i j}=1, \quad \forall i=j, \\
& \tilde{r}_{i j}=\frac{1}{\widetilde{r}_{j i}}, \quad \forall i, j=1,2, \ldots, n .
\end{aligned}
$$

(5) Compute the fuzzy weights of decision factors based on the Lambda-Max method that was proposed by Csutora and Buckley [39]. The procedures are as follows.

(i) Adopt $\alpha$-cut. To do so, set $\alpha=1$ to obtain the positive matrix of expert $k, \widetilde{R}_{b}^{k}=\left[\widetilde{r}_{i j}\right]_{b}^{k}$, and let $\alpha=0$ to acquire the lower and upper bound positive matrixes of expert $k, \widetilde{R}_{a}^{k}=\left[\widetilde{r}_{i j}\right]_{a}^{k}$ and $\widetilde{R}_{c}^{k}=\left[\widetilde{r}_{i j}\right]_{c}^{k}$. Then, figure out the weights of the matrixes, $W_{b}^{k}=\left[w_{i}\right]_{b}^{k}, W_{a}^{k}=\left[w_{i}\right]_{a}^{k}$, and $W_{c}^{k}=\left[w_{i}\right]_{c}^{k}, i=1,2, \ldots, n$ based on the weight calculation procedure introduced in ANP.

(ii) Once the weights of matrixes are obtained, two constants, $M_{a}^{k}$ and $M_{c}^{k}$, are employed to minimize the fuzziness of the weight represented as follows:

$$
\begin{aligned}
& M_{a}^{k}=\min \left\{\frac{w_{i b}^{k}}{w_{i a}^{k}} \mid 1 \leq i \leq n\right\}, \\
& M_{c}^{k}=\max \left\{\frac{w_{i b}^{k}}{w_{i c}^{k}} \mid 1 \leq i \leq n\right\} .
\end{aligned}
$$

Define the upper bound and lower bound of the weight as follows:

$$
\begin{aligned}
& w_{i a}^{* k}=M_{a}^{k} w_{i a}^{k}, \\
& w_{i c}^{* k}=M_{c}^{k} w_{i c}^{k} .
\end{aligned}
$$

(iii) The upper bound and lower bound weight matrixes are

$$
\begin{aligned}
& W_{a}^{* k}=\left[w_{i}^{*}\right]_{a}^{k}, \quad i=1,2, \ldots, n, \\
& W_{c}^{* k}=\left[w_{i}^{*}\right]_{c}^{k}, \quad i=1,2, \ldots, n .
\end{aligned}
$$

The fuzzy weight matrix for expert $\mathrm{k}$ can be obtained by combining $W_{a}^{* k}, W_{b}^{k}$, and $W_{c}^{* k}$. It is defined as $\widetilde{W}_{i}^{k}=\left(w_{i a}^{* k}, w_{i b}^{k}, w_{i c}^{* k}\right), i=1,2, \ldots, n$.

(6) Combine the judgments of all members of the decision making team. Geometric average is used to integrate the fuzzy weight matrixes of experts:

$$
\overline{\widetilde{W}}_{i}=\left(\prod_{k=1}^{K} \widetilde{W}_{i}^{k}\right)^{1 / K}, \quad \forall k=1,2, \ldots, K,
$$

where $\overline{\widetilde{W}}_{i}$ is combined fuzzy weight of decision factor $i$ of $K$ experts. $\widetilde{W}_{i}^{k}$ is fuzzy weight of decision element $i$ of expert $k . K$ is number of expert.

(7) Process the defuzzification to obtain the final ranking order of the decision factors. Based on the equation proposed by Chen [40], the closeness coefficient is defined as follows:

$$
\begin{gathered}
C C_{i}=\frac{d^{-}\left(\overline{\widetilde{W}}_{i}, 0\right)}{d^{*}\left(\overline{\widetilde{W}}_{i}, 1\right)+d^{-}\left(\overline{\widetilde{W}}_{i}, 0\right)}, \\
i=1,2, \ldots, n, \quad 0 \leq C C_{i} \leq 1, \\
d^{-}\left(\overline{\widetilde{W}}_{i}, 0\right)=\sqrt{\frac{1}{3}\left[\left(\bar{W}_{i a}-0\right)^{2}+\left(\bar{W}_{i b}-0\right)^{2}+\left(\bar{W}_{i c}-0\right)^{2}\right]}, \\
d^{*}\left(\overline{\widetilde{W}}_{i}, 1\right)=\sqrt{\frac{1}{3}\left[\left(\bar{W}_{i a}-1\right)^{2}+\left(\bar{W}_{i b}-1\right)^{2}+\left(\bar{W}_{i c}-1\right)^{2}\right]},
\end{gathered}
$$

where $C C_{i}$ is the weight for decision factor $i$ and $d^{-}\left(\overline{\widetilde{W}}_{i}, 0\right)$ and $d^{*}\left(\overline{\widetilde{W}}_{i}, 1\right)$ are the distance measurement between any two fuzzy numbers.

(8) Form super-matrices. First, combine each submatrix with priority vectors to be an initial super-matrix. As it may not fit the column stochastic rule, normalize each column matrix to make a weighted super-matrix. Finally, multiply the weighted super-matrix until $2 k+$ 1 square by formulation (13) to make it converged:

$$
\lim _{k \rightarrow \infty} A^{2 k+1}=\lim _{k \rightarrow \infty} A^{2 k}
$$

\section{Case Study}

The energy company conducted in this study was established in 2005. With the professional team and management, they endeavor to invest in research development, production, and marketing. The major products they develop are lithium-iron phosphate batteries, multifunction display cards, multilevel detection alarm installations, faucet lighting-effects accessory fittings, and lamp structure application of mini night-lights. The products have not only earned the endorsement from domestic manufacturers but also obtained various patents. This company has completed the development of various standardized products such as lithium-iron phosphate battery for vehicle ignition which currently has reached the stage for mass production and sale. In addition, the special design of the protection panel on the product has obtained patens in Taiwan, China, Japan, and Germany and will continue with more patent applications in the United States, Canada, and countries in Europe. Other products such as ultracapacity battery, multifunction portable power supply, and solar-energy charger station are also in hot demand. Today, they continue collaborating with many well-known domestic firms in the development of lithium-iron phosphate battery for vehicles, electric bicycles, electric motorcycles, 
TABLE 1: Critical success factors for the process of NPD.

\begin{tabular}{ll}
\hline Criteria & Subcriteria \\
\hline Characteristics of & Senior management \\
development team (O1) & $\begin{array}{l}\text { Organizational learning (2) } \\
\text { Cross-functional team (3) }\end{array}$ \\
\hline & Customer's needs (4) \\
& $\begin{array}{l}\text { Preliminary market assessment } \\
\text { (5) }\end{array}$ \\
Market trends (O2) & New product advantages (6) \\
& Product innovation (7) \\
New product features & Product specification (8) \\
(O3) & Product identification (9) \\
& Brand awareness (10) \\
\hline & Compatibility product resources \\
Information resources & (11) \\
and technology (O4) & Product design (12) \\
& Production process and \\
& technology (13) \\
\hline & Strategic focus (14) \\
Strategic planning (O5) & Production scheduling (15) \\
& Environmental protection (16) \\
\hline
\end{tabular}

and UPS. The company is trying to make a revolution in the battery industry.

The company aims at development and proxy of the lithium-iron phosphate battery. The characteristics of lithiumiron phosphate battery such as ecofriendly, quick charge, stability, high safety, long lifespan, energy conservation, and carbon reduction do not exist in conventional lead-acid battery. The company would continue to make their efforts for environment and to reach the goal of green energy development. For those reasons, this company is selected in this case study to evaluate the critical success factors and how deep the factors impact on the process of NPD. To achieve this goal, the following steps are taken.

Step 1. The purpose of this step is to identify the evaluation criteria of NPD. To do so, related studies are reviewed and an expert committee is established and consulted. The experts from sales and research and development departments in this company are conducted in this study. Since those committee members have more experiences on the $\mathrm{LiFePO}_{4}$ battery marketing, they are able to point out the critical success factors that affect the NPD process and make this study reliable. According to the previous researches and experts' discussions, the critical success factors consisted of five evaluation criteria and sixteen subcriteria are decided and shown in Table 1.

Step 2. In this step, an interpretive structural modeling (ISM) method is utilized to form a hierarchical structure based on the relationship among the five criteria and within the six 16 subcriteria. ISM methodology suggests the use of group discussion. For this reason, eight experts from the company are consulted in order to identify the nature of contextual relationship among the factors. ISM also builds a network relationship map. The development of ISM method applied to this study is performed in the following steps.

Step 2.1 (forming relation matrix). This step is to form an adjacency matrix that shows the contextual relationship among the factors. To do so, questionnaires are prepared first to identify the contextual relationship between any two criteria or the associated direction of the relation. The responses of the questionnaires given from the experts are then analyzed. In order not to lose most experts' viewpoints, the number of times of the eight experts' judgments on the relationship between each pair of criteria is counted. A threshold value of $88 \%$ is used to determine if the criteria are dependent. That is, if the frequency of the experts' opinions is less than $88 \%$, a 0 is set as there is no influence between the criteria; if the frequency of experts' agreement is greater than or equal to $88 \%$, then a 1 is set. After analyzing the results of the questionnaires, the adjacency matrix $D$ shown in formula (1) is presented.

Step 2.2 (developing reachability matrix). This step is to obtain a reachability matrix as well as check for transitivity. According to formula (2), an initial reachability matrix $M$ that includes self-instructional matrix is gained by adding the matrix $D$ from Step 1 with a unit matrix $I$. For instance, based on sixteen elements in this case study, add up the relation matrix $D$ and a $16 \times 16$ unit matrix $I$, and the initial reachability matrix $M$ will be derived. The algorithm of the Boolean algebra is then used to acquire the final reachability matrix $M^{*}$. The reachability matrix $M^{*}$ is generated by a convergence of the initial reachability matrix $M$ represented in formula (3).

Step 2.3 (building structural model). When all questions have been answered and the reachability matrix is formed, a hierarchical structure is built as shown in Figure 1. According to the reachability matrix $M^{*}$, the relationships between sub criteria under the same cluster (criteria), the interrelationships among sub criteria between the clusters, and the dependencies between clusters under the goal are indicated. The network of the hierarchical structure is established including arrows that denote the direction of relationship between any two factors. The following results give an example to explain the interdependent of the sub criteria under the same cluster illustrated in Figure 1. There is an arrow from factor (1) to factor (3) that means senior management commitment (1) influences cross-functional team (3). Consequently, the rest of the results show that customer's needs (4) influences new product advantages (6), product innovation (7) influences product identification (9), brand awareness (10) influences product specification (8), compatibility product resources (11) influences production process and technology (13), product design (12) influences compatibility product resources (11) as well as production process and technology (13), and strategic focus (14) and production scheduling (15) influence each other.

Step 3. The result of the ISM shows that the feedback and interdependency exist in the critical success factors of 


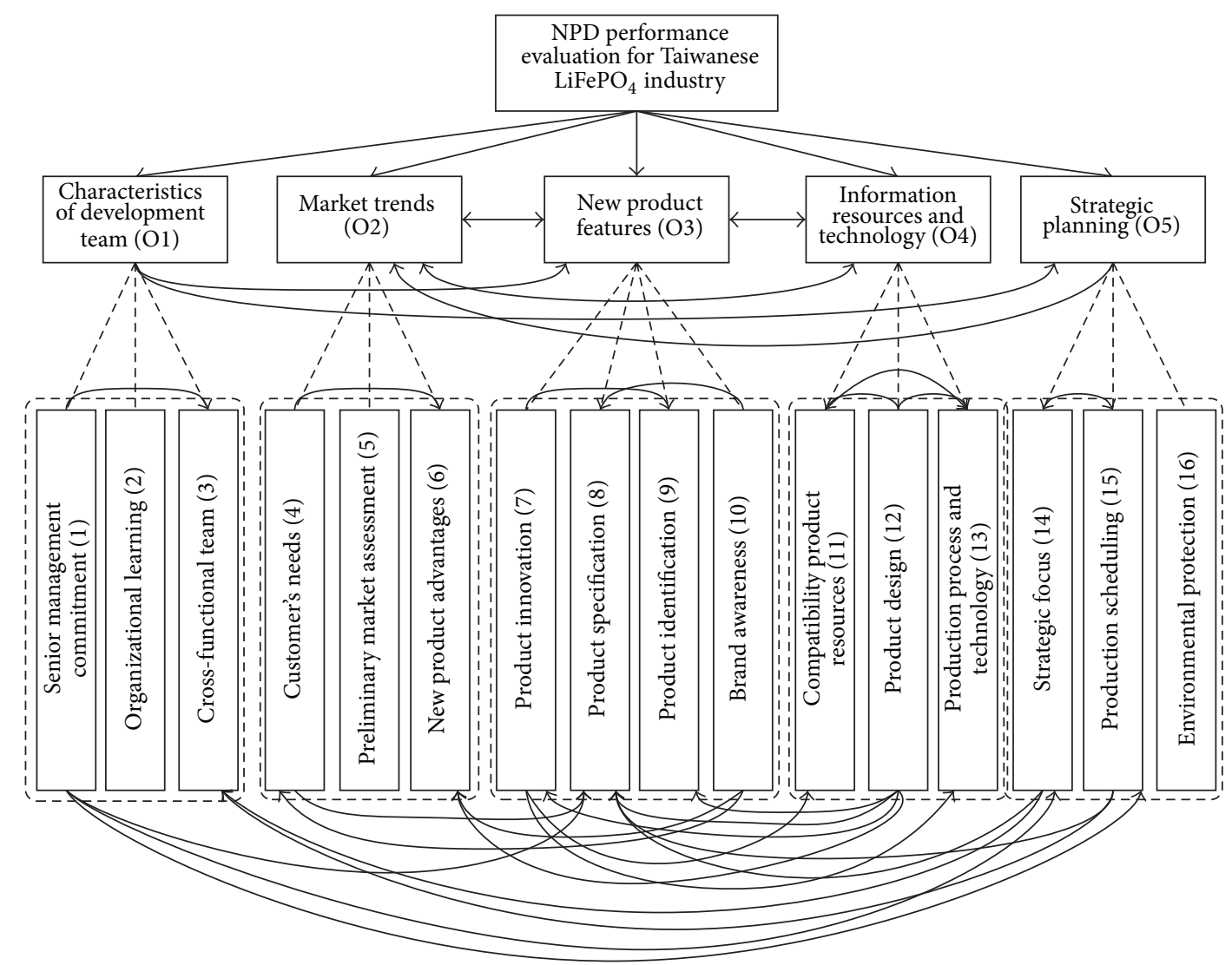

FIGURE 1: Network for the criteria and subcriteria.

the NPD. Based on the relation structure, this step is to derive the weights of the criteria and subcriteria by using a fuzzy analytic network process (FANP) method. The 9point scale of relative importance proposed by Satty in 1980 is employed to develop the FANP questionnaire. Five experts from management, sales, and manufacture departments in this and other $\mathrm{LiFePO}_{4}$ battery companies are conducted in the survey. After they get done the pairwise comparison questionnaires, the weights are calculated. The priority of the critical success factors is analyzed for the decision makers to choose right strategies. The holistic process of the FANP is illustrated as follows.

Step 3.1 (establishing the network structure). A network structure that is consisted of the business goal and the criteria and subcriteria well defined in the first step of this case study is established. This structure includes the relationship of the exterior among the criteria and the relationship of the interior among the subcriteria under each cluster acquired in Step 2.

Step 3.2 (forming pairwise comparison matrices). Based on the 1 to 9 scores received from the expert responses to the FANP questionnaires, the pairwise comparison matrices for the criteria and subcriteria are formed. In the meanwhile, the entries in each column are normalized and the eigenvectors are obtained. A pairwise comparison matrix from an expert's answer to the five criteria is shown in Table 2 as an example.
TABLE 2: Pairwise comparison matrix (expert 1).

\begin{tabular}{lccccc}
\hline $\mathrm{LiFePO}_{4}$ & $(\mathrm{O} 1)$ & $(\mathrm{O} 2)$ & $(\mathrm{O} 3)$ & $(\mathrm{O} 4)$ & $(\mathrm{O} 5)$ \\
\hline$(\mathrm{O} 1)$ & 1 & $1 / 3$ & 2 & 3 & 3 \\
$(\mathrm{O} 2)$ & 3 & 1 & 4 & 7 & 7 \\
$(\mathrm{O} 3)$ & $1 / 2$ & $1 / 4$ & 1 & 2 & 2 \\
$(\mathrm{O} 4)$ & $1 / 3$ & $1 / 7$ & $1 / 2$ & 1 & 1 \\
$(\mathrm{O} 5)$ & $1 / 3$ & $1 / 7$ & $1 / 2$ & 1 & 1 \\
\hline
\end{tabular}

Step 3.3 (examining the consistency). After the eigenvectors are gained, the largest eigenvalue for each matrix can be computed. Then, the consistency index (C.I.), random index (R.I.), and the consistency ratio (C.R.) are figured out. According to Saaty's suggestion, the consistency is satisfied if the C.R. is smaller than 0.1. Thus, the five experts' responses are analyzed through the process described above. The results show all the C.R. is smaller than 0.1. That means the questionnaires are validated. For instance, a consistency examination including C.I., R.I., and C.R. from the same expert's answer to the five criteria is shown in Table 3.

Step 3.4 (constructing fuzzy positive matrices). The scores of each pairwise comparison matrix are converted into linguistic variables, which are represented by positive triangular fuzzy numbers. Table 4 is an example of the fuzzy pairwise 
TABLE 3: Consistency examination for criteria (expert 1).

\begin{tabular}{lcccccc}
\hline $\mathrm{LiFePO}_{4}$ & $(\mathrm{O} 1)$ & $(\mathrm{O} 2)$ & $(\mathrm{O} 3)$ & $(\mathrm{O} 4)$ & $(\mathrm{O} 5)$ & Eigenvector \\
\hline$(\mathrm{O} 1)$ & 1 & $1 / 3$ & 2 & 3 & 3 & 0.21004 \\
$(\mathrm{O} 2)$ & 3 & 1 & 4 & 7 & 7 & 0.52427 \\
$(\mathrm{O} 3)$ & $1 / 2$ & $1 / 4$ & 1 & 2 & 2 & 0.12749 \\
$(\mathrm{O} 4)$ & $1 / 3$ & $1 / 7$ & $1 / 2$ & 1 & 1 & 0.06910 \\
$(\mathrm{O} 5)$ & $1 / 3$ & $1 / 7$ & $1 / 2$ & 1 & 1 & 0.06910 \\
\hline
\end{tabular}

\begin{tabular}{llll}
\hline$\lambda_{\max }=5.17568$ & C.I. $=0.00493$ & R.I. $=1.12$ & C.R. $=\mathbf{0 . 0 0 4 4 1}$
\end{tabular}

TABle 4: Fuzzy pairwise comparison matrix (expert 1).

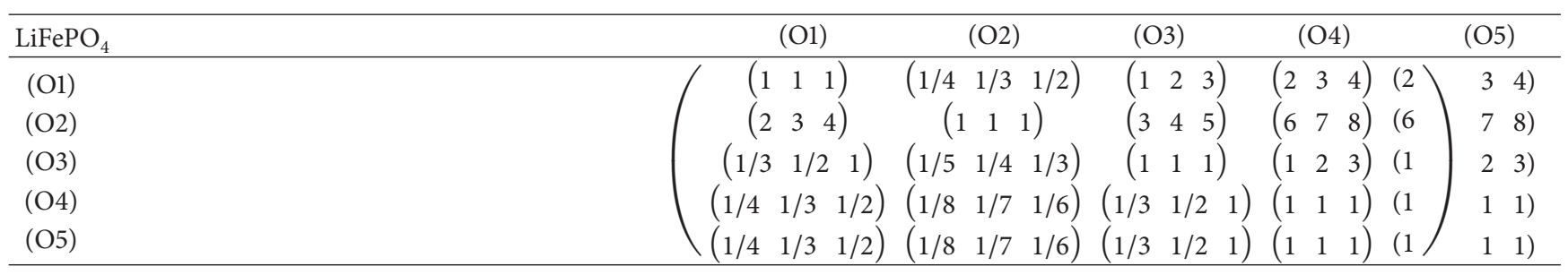

TABLE 5: Fuzzy pairwise comparison matrix (5 experts).

\begin{tabular}{cccccccccccccccc}
\hline & & $(\mathrm{O} 1)$ & \multicolumn{1}{c}{$(\mathrm{O} 2)$} & \multicolumn{1}{c}{ (O3) } & & $(\mathrm{O} 4)$ & & $(\mathrm{O} 5)$ & \\
\hline$(\mathrm{O} 1)$ & 1 & 1 & 1 & $5 / 9$ & $6 / 7$ & $11 / 7$ & 1 & $13 / 5$ & $22 / 9$ & $11 / 6$ & $15 / 9$ & 2 & $11 / 5$ & $12 / 3$ & $21 / 3$ \\
$(\mathrm{O} 2)$ & $7 / 8$ & $11 / 6$ & $17 / 9$ & 1 & 1 & 1 & $22 / 9$ & $33 / 8$ & $43 / 8$ & $12 / 3$ & $23 / 7$ & $34 / 9$ & $12 / 3$ & $23 / 7$ & $34 / 9$ \\
$(\mathrm{O} 3)$ & $4 / 9$ & $5 / 8$ & 1 & $2 / 9$ & $2 / 7$ & $4 / 9$ & 1 & 1 & 1 & $1 / 2$ & $5 / 6$ & $11 / 6$ & $7 / 8$ & $11 / 3$ & $17 / 9$ \\
$(\mathrm{O} 4)$ & $1 / 2$ & $2 / 3$ & $6 / 7$ & $2 / 7$ & $2 / 5$ & $3 / 5$ & $6 / 7$ & $11 / 5$ & 2 & 1 & 1 & 1 & $2 / 3$ & 1 & $15 / 9$ \\
$(\mathrm{O} 5)$ & $3 / 7$ & $3 / 5$ & $5 / 6$ & $1 / 3$ & $2 / 5$ & $2 / 3$ & $5 / 9$ & $3 / 4$ & $11 / 7$ & $2 / 3$ & 1 & $15 / 9$ & 1 & 1 & 1 \\
\hline
\end{tabular}

TABLE 6: Result of defuzzification.

\begin{tabular}{|c|c|c|c|c|c|c|}
\hline $\mathrm{LiFePO}_{4}$ & (O1) & $(\mathrm{O} 2)$ & (O3) & (O4) & (O5) & Eigenvector \\
\hline$(\mathrm{O} 1)$ & 1.0000 & 0.8533 & 1.6216 & 1.5919 & 1.7279 & 0.23549 \\
\hline$(\mathrm{O} 2)$ & 1.2764 & 1.0000 & 3.3236 & 2.5024 & 2.5024 & 0.35487 \\
\hline (O3) & 0.6751 & 0.3252 & 1.0000 & 0.8335 & 1.3242 & 0.13174 \\
\hline (O4) & 0.6610 & 0.4372 & 1.3544 & 1.0000 & 1.0654 & 0.14968 \\
\hline (O5) & 0.6228 & 0.4817 & 0.8225 & 1.0654 & 1.0000 & 0.12822 \\
\hline$\lambda_{\max }=5.04049$ & & C.I. $=0.01012$ & & R.I. $=1.12$ & \multicolumn{2}{|c|}{ C.R. $=0.00904$} \\
\hline
\end{tabular}

comparison matrix received from the same expert's responses to the five criteria.

Step 3.5 (integrating the opinions of decision makers). After the five pairwise comparison matrixes are converted to fuzzy matrixes, geometric average is used to combine all the fuzzy weights of the experts. The results in this step are presented in triangular fuzzy numbers as in Table 5.

Step 3.6 (defuzzification). In this step, the triangular fuzzy numbers are transformed to fixed numbers. Based on the equation proposed by Chen [40], Table 6 shows the result matrix along with eigenvectors and validation consistency after processing defuzzification from Table 5.

Step 3.7 (forming super-matrix). Before forming the supermatrices, all the pairwise comparison matrixes need to be ready like the example shown in Table 6. Then, an initial super-matrix can combine the criteria and each submatrix with eigenvectors represented in Table 7. If the entries in the initial super-matrix do not fit the column stochastic rule, each column matrix has to be normalized to make a weighted super-matrix shown in Table 8. Finally, the weighted supermatrix is multiplied until it is converged and a converged super-matrix is formed as in Table 9.

Step 3.8 (obtain the priority of total weight for evaluation). The evaluation model is obtained in this final step. To do so, each group in the converged super-matrix needs to be normalized and the individual weights can be derived. The weight of criteria multiplied by the individual weight is the total weight. The results establish the evaluation model and are shown in Table 10. 


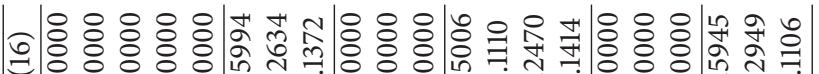

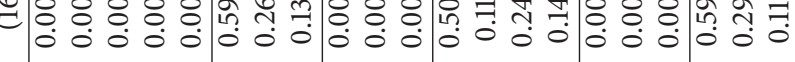

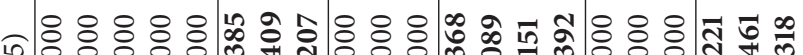

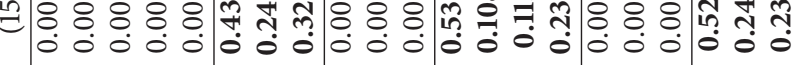

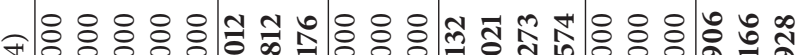

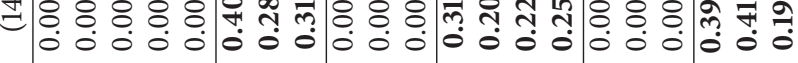

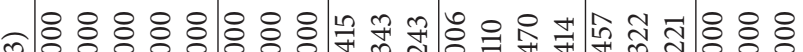

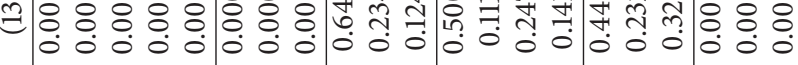

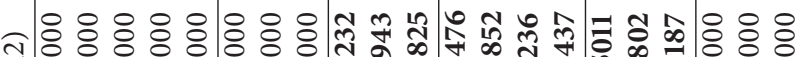
İla 융ㅇㅇㅇㅇㅇㅇㅠ

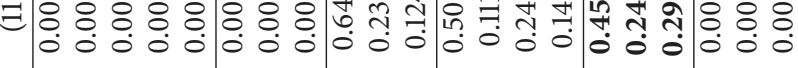

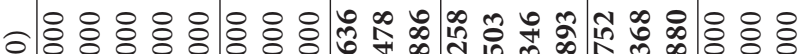

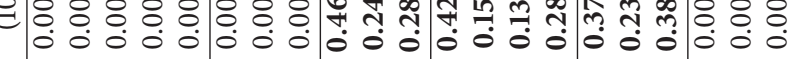

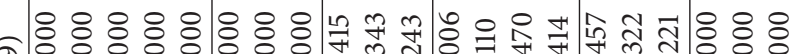

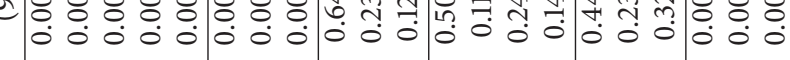

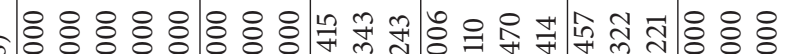

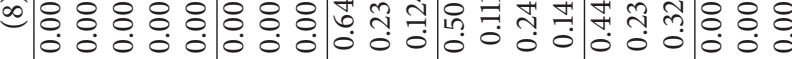

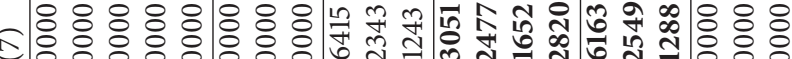

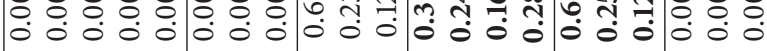
๑

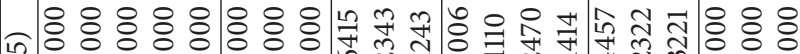

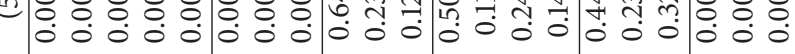

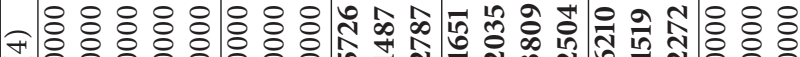

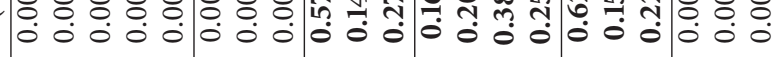

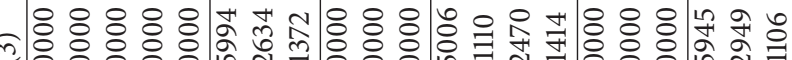
N

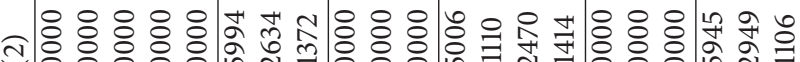
¿

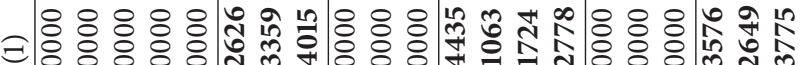

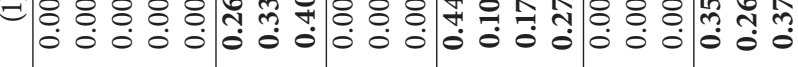

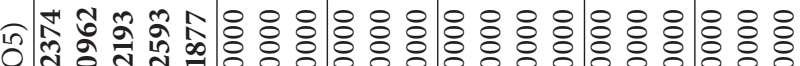

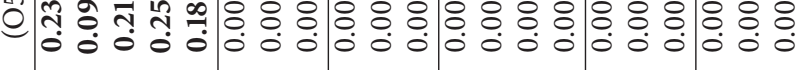
厄商

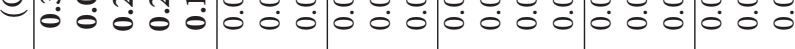
厄̂

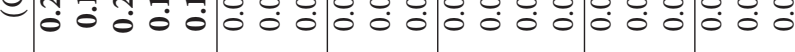

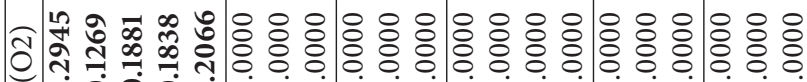

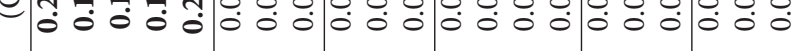
ฮิ)

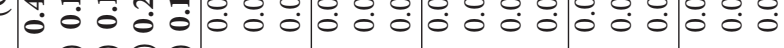

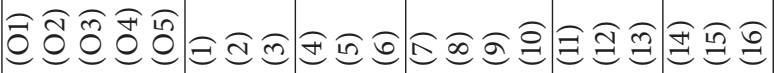




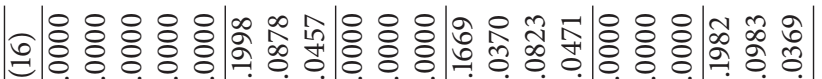

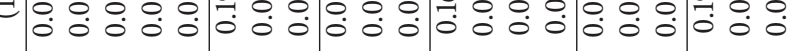

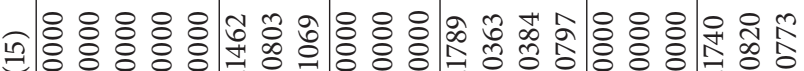

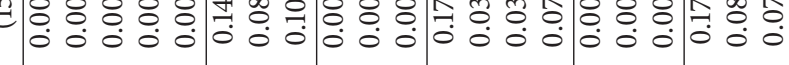

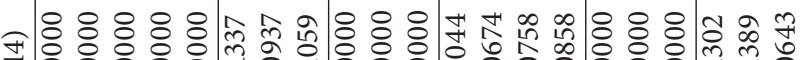

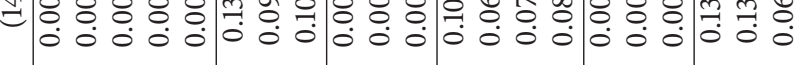

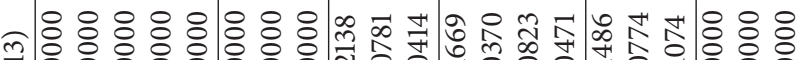

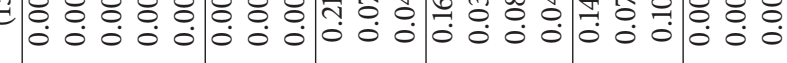
ส

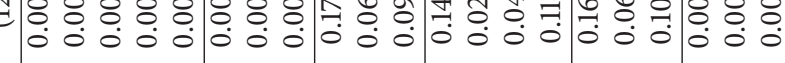

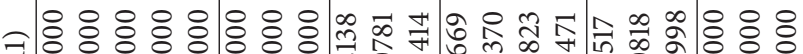

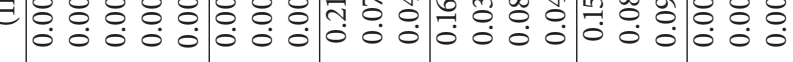

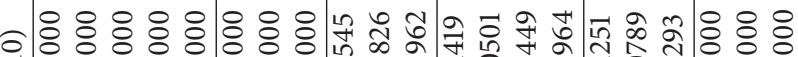

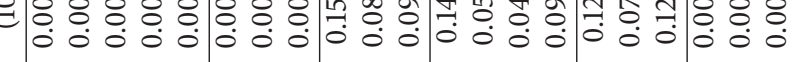
人

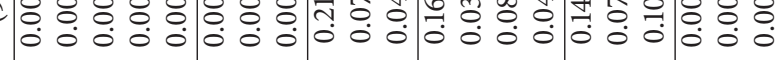

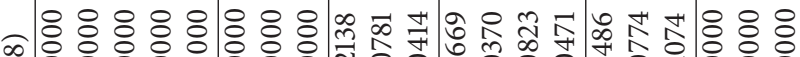

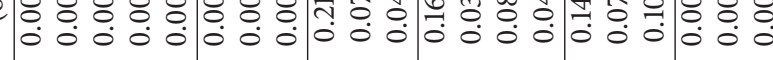

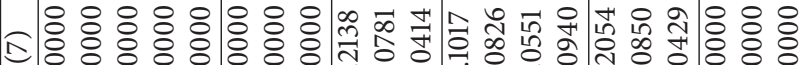

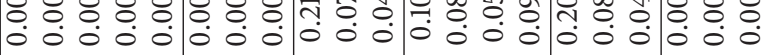

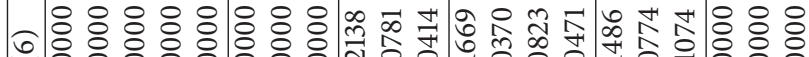

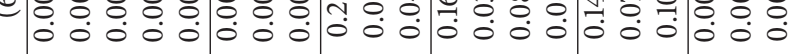

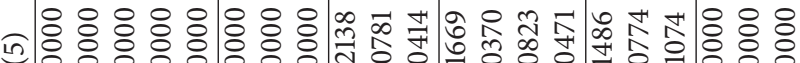

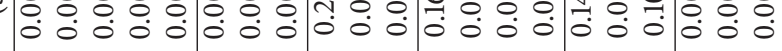

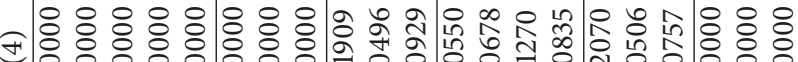

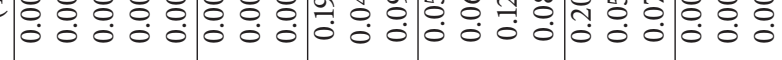
๙

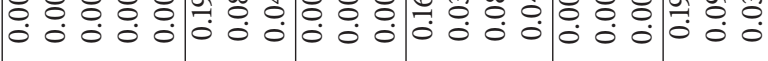
ส

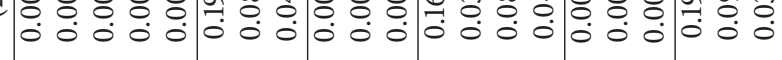
=

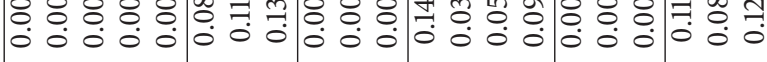

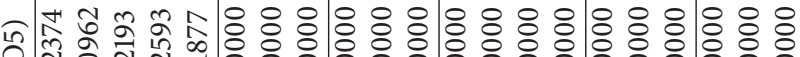

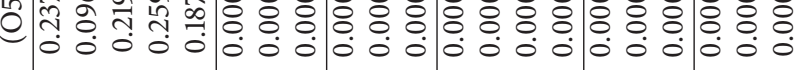
Æ

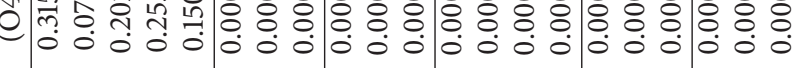
๙

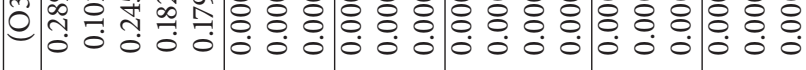

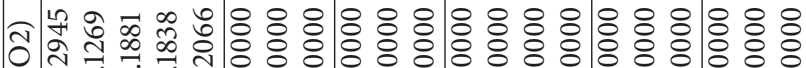

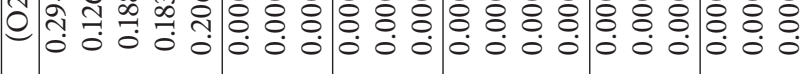
○)

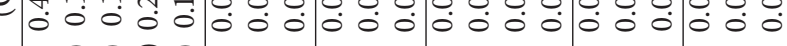

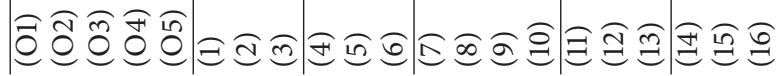




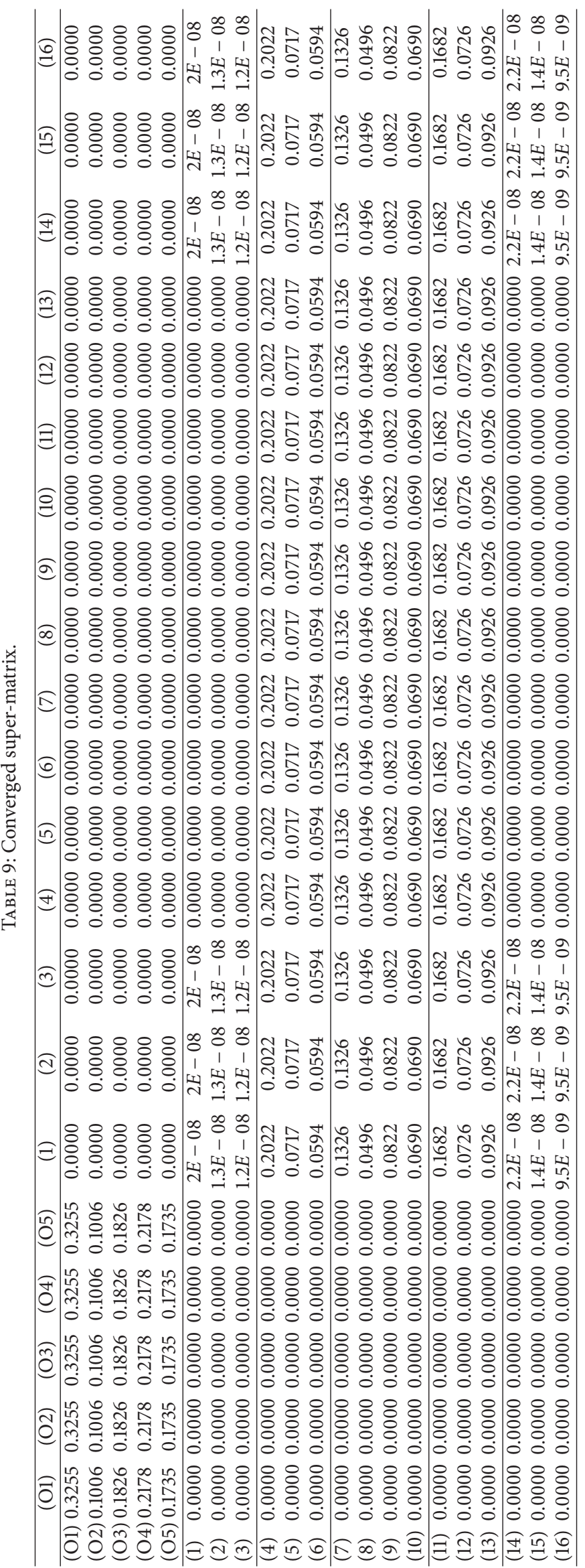


TABLE 10: Weights after normalization.

\begin{tabular}{|c|c|c|c|}
\hline Criteria & Subcriteria & FANP weight & Ranking \\
\hline \multirow{3}{*}{$\begin{array}{l}\text { Characteristics of } \\
\text { development team (O1) } \\
0.3255\end{array}$} & Senior management commitment (1) & 0.0000 & 11 \\
\hline & Organizational learning (2) & 0.0000 & 11 \\
\hline & Cross-functional team (3) & 0.0000 & 11 \\
\hline \multirow{3}{*}{$\begin{array}{l}\text { Market trends }(\mathrm{O} 2) \\
0.1006\end{array}$} & Customer's needs (4) & 0.6067 & 1 \\
\hline & Preliminary market assessment (5) & 0.2150 & 7 \\
\hline & New product advantages (6) & 0.1783 & 9 \\
\hline \multirow{4}{*}{$\begin{array}{l}\text { New product features }(\mathrm{O} 3) \\
0.1826\end{array}$} & Product innovation $(7)$ & 0.3978 & 3 \\
\hline & Product specification (8) & 0.1487 & 10 \\
\hline & Product identification (9) & 0.2465 & 5 \\
\hline & Brand awareness (10) & 0.2070 & 8 \\
\hline \multirow{3}{*}{$\begin{array}{l}\text { Information resources and } \\
\text { technology }(\mathrm{O} 4) 0.2178\end{array}$} & Compatibility product resources (11) & 0.5045 & 2 \\
\hline & Product design (12) & 0.2177 & 6 \\
\hline & Production process and technology (13) & 0.2777 & 4 \\
\hline \multirow{3}{*}{$\begin{array}{l}\text { Strategic planning }(\mathrm{O} 5) \\
0.1735\end{array}$} & Strategic focus $(14)$ & 0.0000 & 11 \\
\hline & Production scheduling (15) & 0.0000 & 11 \\
\hline & Environmental protection (16) & 0.0000 & 11 \\
\hline
\end{tabular}

According to the weight listed in Table 10, the most important factor is customer's needs (0.6067) in market trends (0.1006). The results show that firms have to emphasize on marketing which is the management process responsible for identifying, anticipating, and satisfying customer requirements. The second important factor is compatibility product resources $(0.5045)$ under information resources and technology (0.2178). Firms should consider information and technology more about the product resource compatibility so as to shorten the develop time and decrease the production risky and cost. The third important one is product innovation $(0.3978)$ in new product features $(0.1826)$. Firms have to devote more efforts to make a new product creative. The results, in fact, show that firms ought to concentrate their attention more on the top three critical success factors of customer needs, compatibility product resources, and product innovation than on the other factors.

\section{Conclusion}

Successful new product development projects have been considered the key point for $\mathrm{LiFePO}_{4}$ battery firms to win an advantage over others. However, selecting the right strategies for NPD has been a difficult task since the problems are complicated and often conflicting criteria. Most existing models seem to lack a feasible solution. Even though plenty previous studies propose performance assessment models for many different industries, no one gives a suggestion for the $\mathrm{LiFePO}_{4}$ battery industry. In addition, although continuous efforts have been improving the performance of $\mathrm{LiFePO}_{4}$ batteries that focus on the battery development, a discussion on evaluation of NPD for $\mathrm{LiFePO}_{4}$ batteries is rare.

The $\mathrm{LiFePO}_{4}$ battery industry is currently one of the most valuable industries in the world. However, since more and more Taiwanese firms invest huge amount of money in the $\mathrm{LiFePO}_{4}$ batteries, they are facing an extremely competitive and cost-cutting war. The increasing demand for $\mathrm{LiFePO}_{4}$ batteries has led the firms and academics to stress on new product development (NPD) projects concerning the environment friendly topics to gain and maintain a competitive edge. However, not all of the NPD tactics could reach the business goal and keep the competitive advantage. The strategies of proposed solution must be precisely evaluated to see if they meet the business's objectives before they move forward.

This study proposes a MCDM model based on appropriate methods including ISM, fuzzy set theory, and ANP. This systemic approach presents a real-world case study and demonstrates the value. This hybrid model helps the $\mathrm{LiFePO}_{4}$ battery firm make right decisions for new product development processes in Taiwan. As the presented model is successful, it can be applied to other firms in the industry. With correct strategies, it is believed that the $\mathrm{LiFePO}_{4}$ battery firms in Taiwan are easier to build sustainable competitive advantage over their competitors in Taiwan or other countries and avoid undesired impact on the firms.

\section{Conflict of Interests}

The authors declare that there is no conflict of interests regarding the publication of this paper.

\section{References}

[1] D. R. Chang and H. Cho, "Organizational memory influences new product success," Journal of Business Research, vol. 61, no. 1, pp. 13-23, 2008.

[2] K.-L. Chang, "Combined MCDM approaches for centuryold Taiwanese food firm new product development project selection," British Food Journal, vol. 115, no. 8, pp. 1197-1210, 2013. 
[3] S. H. Liao, C. L. Hsieh, and S. P. Huang, "Mining product maps for new product development," Expert Systems with Applications, vol. 34, no. 1, pp. 50-62, 2008.

[4] K. J. Wang, Y. H. Lee, S. Wang, and C. P. Chu, "erformance evaluation of resource allocation strategies for new product development under different workload scenarios," Journal of Modelling in Management, vol. 4, no. 2, pp. 91-113, 2009.

[5] T. J. Marion, J. H. Friar, and T. W. Simpson, "New product development practices and early-stage firms: two in-depth case studies," Journal of Product Innovation Management, vol. 29, no. 4, pp. 639-654, 2012.

[6] A. H. I. Lee and C.-Y. Lin, "An integrated fuzzy QFD framework for new product development," Flexible Services and Manufacturing Journal, vol. 23, no. 1, pp. 26-47, 2011.

[7] K. T. Ulrich and S. D. Eppinger, Product Design and Development, McGraw-Hill, New York, NY, USA, 2012.

[8] A. K. Padhi, K. S. Nanjundaswamy, and J. B. Goodenough, "Phospho-olivines as positive-electrode materials for rechargeable lithium batteries," Journal of the Electrochemical Society, vol. 144, no. 4, pp. 1188-1194, 1997.

[9] J. B. Goodenough, "Rechargeable batteries: challenges old and new," Journal of Solid State Electrochemistry, vol. 16, no. 6, pp. 2019-2029, 2012.

[10] B. L. Ellis, T. N. Ramesh, W. N. Rowan-Weetaluktuk, D. H. Ryan, and L. F. Nazar, "Solvothermal synthesis of electroactive lithium iron tavorites and structure of $\mathrm{Li}_{2} \mathrm{FePO}_{4} \mathrm{~F}$," Journal of Materials Chemistry, vol. 22, no. 11, pp. 4759-4766, 2012.

[11] J. J. Wang and X. L. Sun, "Understanding and recent development of carbon coating on $\mathrm{LiFePO}_{4}$ cathode materials for lithium-ion batteries," Energy \& Environmental Science, vol. 5, no. 1, pp. 5163-5185, 2012.

[12] L. X. Yuan, Z. H. Wang, W. X. Zhang et al., "Development and challenges of $\mathrm{LiFePO}_{4}$ cathode material for lithium-ion batteries," Energy and Environmental Science, vol. 4, no. 2, pp. 269-284, 2011.

[13] A. P. Sage, Interpretive Structural Modeling: Methodology for Large-Scale System, McGraw-Hill, New York, NY, USA, 1977.

[14] J. N. Warfield, "Toward interpretation of complex structural models," IEEE Transactions on Systems, Man, and Cybernetics, vol. 4, no. 5, pp. 405-417, 1974.

[15] J. N. Warfield, "Developing interconnection matrices in structural modeling," IEEE Transactions on Systems, Man, and Cybernetics, vol. SMC-4, no. 1, pp. 81-87, 1974.

[16] J. N. Warfield, Societal Systems Planning, Policy and Complexity, John Wiley \& Sons, New York, NY, USA, 1976.

[17] K. K. Tatsuoka, "Architecture of knowledge structures and cognitive diagnosis: a statistical pattern recognition and classification approach," in Cognitively Diagnostic Assessment, chapter 14, pp. 327-359, Lawrence Erlbaum Associates, Mahwah, NJ, USA, 1995.

[18] R. Attri, N. Dev, and V. Sharma, "Interpretive structural modelling (ISM) approach: an overview," Research Journal of Management Sciences, vol. 2, no. 2, pp. 3-8, 2013.

[19] T. Raj and R. Attri, "Identification and modelling of barriers in the implementation of TQM," International Journal of Productivity and Quality Management, vol. 8, no. 2, pp. 153-179, 2011.

[20] T. Raj, R. Attri, and V. Jain, "Modelling the factors affecting flexibility in FMS," International Journal of Industrial and Systems Engineering, vol. 11, no. 4, pp. 350-374, 2012.

[21] R. Attri, S. Grover, N. Dev, and D. Kumar, "Analysis of barriers of total productive maintenance (TPM)," International Journal of Systems Assurance Engineering and Management, vol. 4, no. 4, pp. 365-377, 2013.

[22] R. Attri, S. Grover, N. Dev, and D. Kumar, "An ISM approach for modelling the enablers in the implementation of Total Productive Maintenance (TPM)," International Journal of System Assurance Engineering and Management, vol. 4, no. 4, pp. 313326, 2013.

[23] V. Anantatmula and S. Kanungo, "Role of IT and KM in improving project management performance," VINE, vol. 38, no. 3, pp. 357-369, 2008.

[24] S. Bhattacharya and K. Momaya, "Interpretive structural modeling of growth enablers in construction companies," Singapore Management Review, vol. 31, no. 1, pp. 73-97, 2009.

[25] W.-M. Wang, A. H. I. Lee, L.-P. Peng, and Z.-L. Wu, "An integrated decision making model for district revitalization and regeneration project selection," Decision Support Systems, vol. 54, no. 2, pp. 1092-1103, 2013.

[26] T. L. Saaty, "A scaling method for priorities in hierarchical structures," Journal of Mathematical Psychology, vol. 15, no. 3, pp. 234-281, 1977.

[27] T. L. Saaty, The Analytic Network Process: Decision Making with Dependence and Feedback, RWS Publication, Pittsburgh, Pa, USA, 2001.

[28] L. Mikhailov and M. G. Singh, "Fuzzy analytic network process and its application to the development of decision support systems," IEEE Transactions on Systems, Man and Cybernetics C: Applications and Reviews, vol. 33, no. 1, pp. 33-41, 2003.

[29] M. A. B. Promentilla, T. Furuichi, K. Ishii, and N. Tanikawa, "A fuzzy analytic network process for multi-criteria evaluation of contaminated site remedial countermeasures," Journal of Environmental Management, vol. 88, no. 3, pp. 479-495, 2008.

[30] G. Büyüközkan, T. Ertay, C. Kahraman, and D. Ruan, "Determining the importance weights for the design requirements in the house of quality using the fuzzy analytic network approach," International Journal of Intelligent Systems, vol. 19, no. 5, pp. 443-461, 2004.

[31] R. P. Mohanty, R. Agarwal, A. K. Choudhury, and M. K. Tiwari, "A fuzzy ANP-based approach to R\&D project selection: a case study," International Journal of Production Research, vol. 43, no. 24, pp. 5199-5216, 2005.

[32] M. Sevkli, A. Oztekin, O. Uysal, G. Torlak, A. Turkyilmaz, and D. Delen, "Development of a fuzzy ANP based SWOT analysis for the airline industry in Turkey," Expert Systems with Applications, vol. 39, no. 1, pp. 14-24, 2012.

[33] W.-C. Chen and H.-P. Chang, "The application of fuzzy ANP in the development of new product decision-making-a case study of the solar module industry," Advanced Materials Research, vol. 472-475, pp. 1333-1338, 2012.

[34] N. Rezaeiniya, A. S. Ghadikolaei, J. M. Tekmeh, and H. Rezaeiniya, "Fuzzy ANP approach for new application: Greenhouse Location selection; a case in Iran," Journal of Mathematics and Computer Science, vol. 8, no. 1, pp. 1-20, 2014.

[35] K. Govindan, R. Khodaverdi, and A. Jafarian, "A fuzzy multi criteria approach for measuring sustainability performance of a supplier based on triple bottom line approach," Journal of Cleaner Production, vol. 47, pp. 345-354, 2013.

[36] T. L. Saaty, The Analytic Hierarchy Process, McGraw-Hill, New York, NY, USA, 1980.

[37] T. L. Saaty, "How to make a decision: the analytic hierarchy process," Interfaces, vol. 24, no. 6, pp. 19-43, 1994. 
[38] J. J. Buckley, "Fuzzy hierarchical analysis," Fuzzy Sets and Systems, vol. 17, no. 3, pp. 233-247, 1985.

[39] R. Csutora and J. J. Buckley, "Fuzzy hierarchical analysis: the Lambda-Max method," Fuzzy Sets and Systems, vol. 120, no. 2, pp. 181-195, 2001.

[40] C. T. Chen, "Extensions of the TOPSIS for group decisionmaking under fuzzy environment," Fuzzy Sets and Systems, vol. 114, no. 1, pp. 1-9, 2000. 


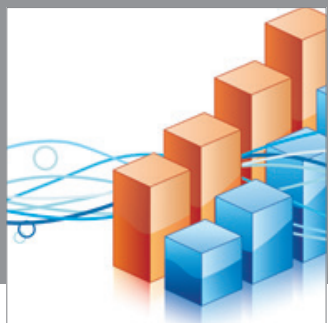

Advances in

Operations Research

mansans

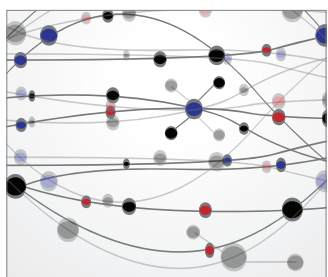

The Scientific World Journal
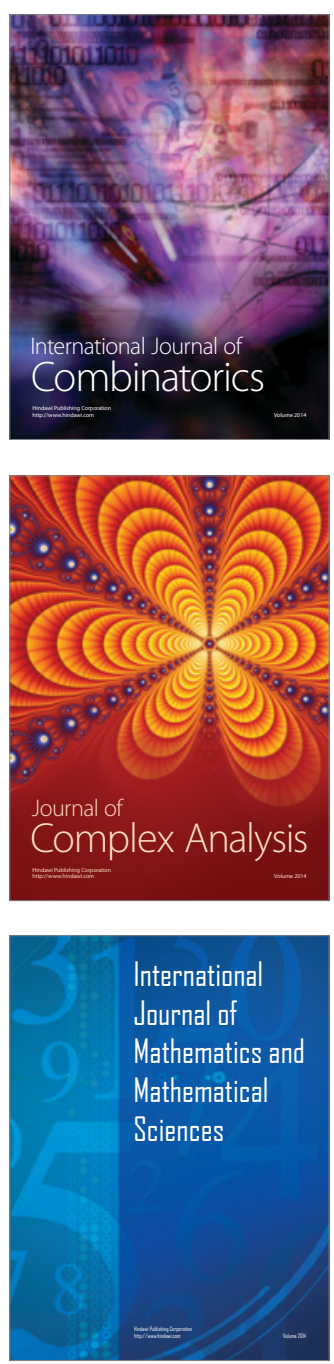
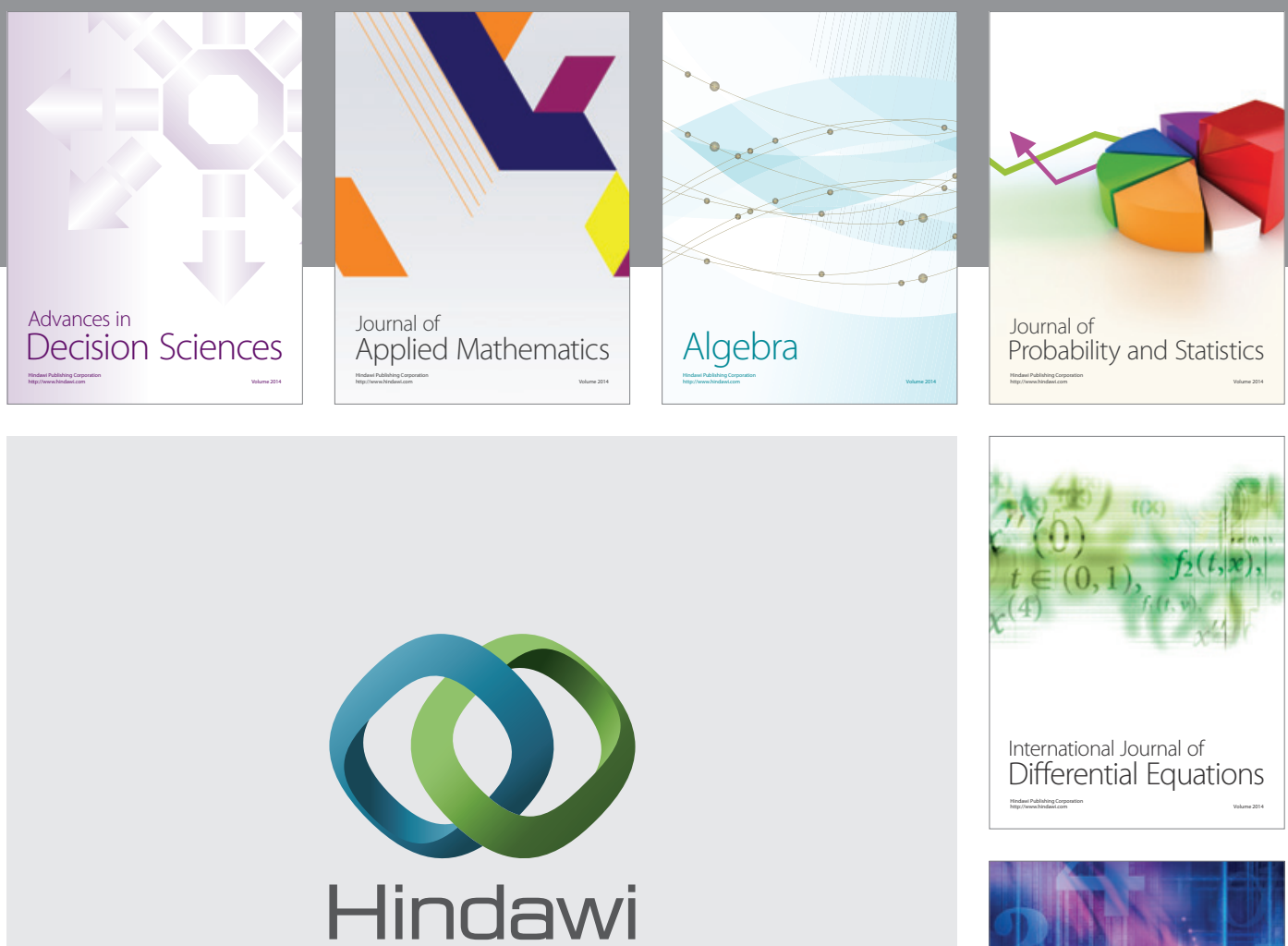

Submit your manuscripts at http://www.hindawi.com
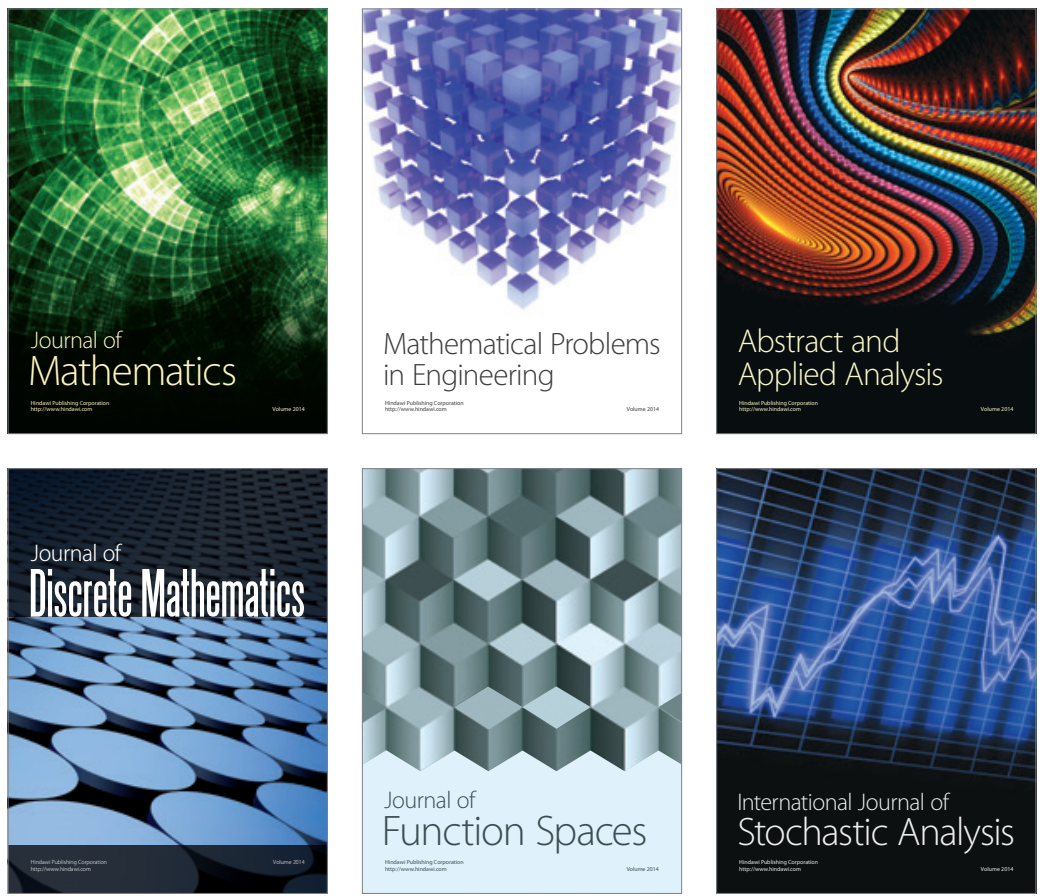

Journal of

Function Spaces

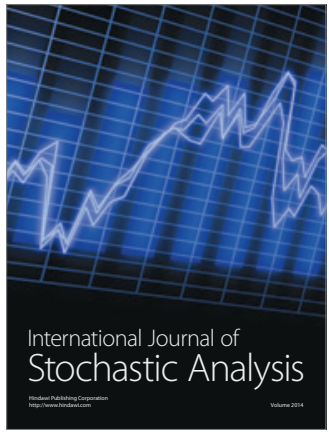

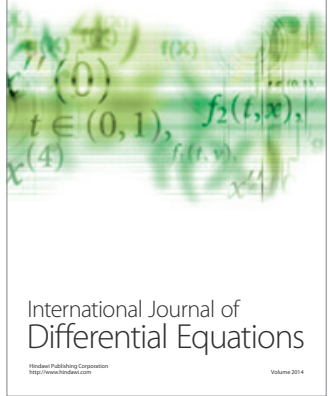
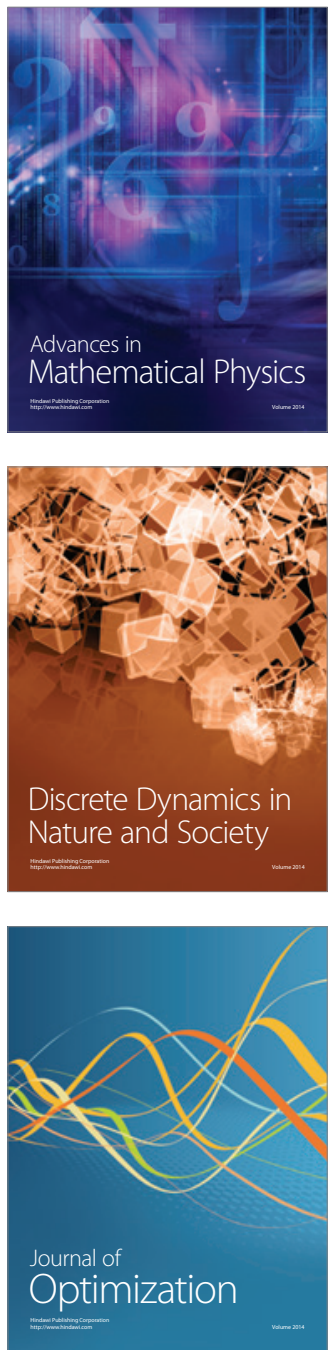